\title{
Is There a Possible Association between Dietary Habits and Benign Paroxysmal Positional Vertigo in the Elderly? The Importance of Diet and Counseling
}

\author{
Adriane Rocha Schultz ${ }^{1}$ Rejane Dias Neves-Souza ${ }^{2}$ Viviane de Souza Pinho Costa ${ }^{3}$ \\ Caroline Luiz Meneses-Barriviera ${ }^{4}$ Pricila Perini Rigotti Franco ${ }^{5}$ Luciana Lozza de Moraes Marchiori ${ }^{5}$
}

${ }^{1}$ MSc in Rehabilitation Sciencies, Unopar, Londrina, Paraná, Brazil

2 Nutrition, Unopar, Londrina, Paraná, Brazil

${ }^{3}$ Department of Health Sciences, Centre of Biological and Health Sciences (CCBS), Universidade Norte do Paraná (UNOPAR), Londrina, Paraná, Brazil

${ }^{4}$ Department of Rehabilitation Sciences, UEL/UNOPAR, Londrina,

Paraná, Brazil

${ }^{5}$ Fonoaudiolgia, Universidade Norte do Paraná, Londrina,

Paraná, Brazil

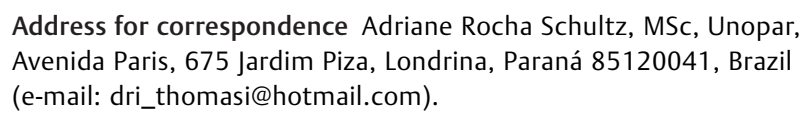

Address for correspondence Adriane Rocha Schultz, MSc, Unopar, Avenida Paris, 675 Jardim Piza, Londrina, Paraná 85120041, Brazil (e-mail: dri_thomasi@hotmail.com).

Int Arch Otorhinolaryngol 2015;19:293-297.

\begin{abstract}
Introduction Poor diet habits and inadequate intake of nutrients are a concern in the elderly. Nutritional education with guidance may improve the results of the treatment of vertigo.

Objective Evaluate the presence of benign paroxysmal positional vertigo (BPPV) associated with feeding habits.

Methods Cross-sectional study with elderly people living independently. We evaluated nutritional habits through the method of dietary 24-hour recall and manipulation of DixHallpike.

Results Based on a sample of 487 individuals, 117 had BPPV. Among the 117 elderly patients with BPPV, 37 (31.62\%) had inadequate feeding. From those 370 individuals without BPPV, 97 (26.21\%) had inappropriate feeding. No significant association between nutritional habits and BPPV in the total population was observed $(p=0.3064)$. However, there was significant relation between BPPV and inadequate carbohydrate intake $(p=0.0419)$ and insufficient fiber intake $(p=0.03)$, and the diet of these subjects was rich in polyunsaturated fatty acids $(p=0.0084)$.

Conclusion These data correlate with the dyslipidemia and hypertriglyceridemia

Keywords

- dizziness

- aging

- nutrition status, making it extremely important to reduce the intake of fats and carbohydrates and increase the fiber intake to stabilize triglycerides and thus minimize harmful effects on the inner ear. Food readjustment is suggested in patients with BPPV, along with the work of a multidisciplinary team to improve the quality of the elderly.
\end{abstract}

received

December 2, 2014

accepted

March 29, 2015

published online

May 29, 2015
DOI http://dx.doi.org/

10.1055/s-0035-1551551. ISSN 1809-9777.
Copyright $\odot 2015$ by Thieme Publicações License terms

Ltda, Rio de Janeiro, Brazil 


\section{Introduction}

The elderly are at risk for nutritional disorders and malnutrition, including undernutrition and nutrient deficiencies and imbalances. Several age-related physical, clinical, economic, and social factors can compromise nutritional status; furthermore, changes in the body composition of elderly people and sedentary lifestyles reduce energy requirements and daily energy intakes. The highly intercorrelated nature of the consumption of dietary components makes it difficult to evaluate specific unconfounded effects through observational studies. $^{1,2}$

Eating patterns have been considered risk factors for various metabolic and circulatory changes that cause several symptoms including dizziness, especially among elderly individuals. ${ }^{3,4}$ Dizziness is a change in balance characterized by the illusion of movement of the individual or the environment that surrounds them. Rotational dizziness is called vertigo. ${ }^{5}$ This symptom is highly prevalent worldwide, affecting $\sim 2 \%$ of young adults, $30 \%$ at 65 years, and up to $50 \%$ in the elderly over 85 years. ${ }^{6}$

Especially in the elderly, a lack of regular physical activity, low level of physical fitness, and nutritional disorders are risk factors for several metabolic and circulatory changes that cause various symptoms, such as dizziness and even benign paroxysmal positional vertigo (BPPV). ${ }^{1,7}$

Current evidence shows that good dietary habits in the elderly can improve their quality of life. The prevalence of malnutrition is increasing in this population and is associated with declines in functional status, impaired muscle function, decreased bone mass, immune dysfunction, anemia, reduced cognitive function, poor wound healing, delayed recovery from surgery, higher hospital readmission rates, and mortality. ${ }^{8}$

Malnutrition is defined as a state in which a deficiency, excess, or imbalance of energy, protein, and other nutrients causes adverse effects on body form, function, and clinical outcome. $^{9}$

There is evidence to suggest that dietary habits such as low sodium can alter inner ear fluid homeostasis and auditory function. The experiments indicate that the endolymph compartment has a built-in mechanism for maintaining a low-sodium concentration while keeping ionic balance with the surrounding perilymph and serum. ${ }^{10}$

The labyrinth system, which depends on a continuous supply of energy, is influenced by the circulating levels of glucose and hormones, which depend on the generation of energy by adenosine triphosphate. Data in the literature estimate that the occurrence of glucose metabolic disorder is between 42 and $80 \%$ in patients with tinnitus and dizziness, whereas 2.5 to $15 \%$ of the population presents asymptomatic hypoglycemia or some affection of glucose tolerance curves. In Brazil, glucose metabolic disorder has already been considered the most frequent cause of labyrinthic metabolic dysfunctions. ${ }^{11,12}$

Vertigo is the most common type of dizziness and BPPV is the most common cause of vertigo in adults. It has an estimated prevalence of $3.2 \%$ in women and $1.6 \%$ in men. It is considered the most common cause of dizziness in the elderly, and $30 \%$ of people had the condition at least once. ${ }^{13,14}$

In the United States, BPPV has an estimated prevalence of $2.4 \%$ in the general adult population, and although this disorder affects people throughout life, it tends to affect individuals aged 50 to 70 years and therefore affects payroll taxes and the health. ${ }^{15}$

Based on the considerations presented, this study aimed to investigate the possible association between the presence of BPPV with the practice of food habits in the elderly.

\section{Methods}

This cross-sectional study was approved by the Human Research Ethics Committee. ${ }^{16}$ It is part of a broader investigation, the EELO Project (from Portuguese: studies on aging and longevity), which has been conducted in Londrina since 2009 . The city of Londrina $(\sim 500,000$ inhabitants) is situated in the north region of Paraná state, Brazil. The city has a population of 43,610 elderly people enrolled in the 38 primary care units in the urban city area. The sample was a randomly stratified set, considering the gender and the five regions of the city ( $15 \%$ from the central region, $27 \%$ from the northern region, $23 \%$ from the southern region, $19 \%$ from the eastern region, and $16 \%$ from the western region). The study included individuals aged 60 years and over, of both genders, who were living independently and classified at level 3 or 4 as proposed by Spidurso. ${ }^{17}$ This classification evaluates the independence level of the elderly, with level 1 indicating a lack of self-mobility and level 5 indicating athletes. Elderly who had any illness or limitation that would prevent the testing, such as physical or mental disabilities, were excluded from the sample. All the participants signed an informed consent form. Four hundred ninety-six subjects were included in this part of the study. BPPV was found in 117, and 53 of them had recurrent BPPV confirmed by the questionnaire.

The dietary information was collected by means of the dietary 24-hour recall methods. ${ }^{18}$ The interviews were conducted on three different days: one day on the weekend and two in the middle of the week. With the aid of photo album with pictures of portion sizes and foods, the interviews took place with notation of the food consumed in the order of dialed meals. The types of food, the quantities consumed, and how they were prepared were recorded. The quantities of these foods were reported in household measures and converted into grams or milliliters. Dietary data were processed and analyzed with the nutritional evaluation software Avanutri online. ${ }^{19}$ The analysis of dietary intake of protein, carbohydrate, lipid, fiber, and cholesterol took into account the recommended dietary reference intakes. ${ }^{20}$

The presence of vertigo was established through questions about vertigo (attacks, symptoms, and familiar history of vertigo), and the diagnosis of BPPV among study participants with vertigo was established with the Dix-Hallpike maneuver and answers on the questionnaire about vertigo. ${ }^{21}$

The chi-square test was performed, and $p \leq 0.05$ was considered statistically significant. The significance of food 
habit variables and the variables carbohydrates, polyunsaturated fat, monounsaturated fat, saturated fat, lipids, protein, and fiber were all considered.

\section{Results}

Based on a sample of 487 subjects, 117 had BPPV and 370 did not. Of 117 elderly patients with BPPV, 37 (31.62\%) had inadequate nutrition. Of the 370 without BPPV, 97 (26.21\%) had inadequate nutrition.

We did not observe a significant association $(p=0.3064)$ between food habits and BPPV in the total population (odds ratio $=1.3017$; - Table $\mathbf{1}$ ).

Of the 117 people who had BPPV, 102 (87.17\%) had inadequate carbohydrate intake and 15 (12.82\%) did not. And of the 370 people without BPPV, 330 (89.18\%) had inadequate carbohydrate intake and 40 (10.81\%) had normal intake. The Mann-Whitney test was used for statistical analysis between inadequate carbohydrates and BPPV and gave a value of $U=19,351.50$ and $p=0.0419$, a statistically significant difference (see - Table 2).

Of the 117 people who had BPPV, 82 (70.08\%) had polyunsaturated fat intake and 35 (29.91\%) did not. Of the 370 people without BPPV, 289 (78.10\%) had polyunsaturated fat intake and 81 (21.89\%) did not. For statistical analysis between polyunsaturated fat and BPPV, we performed the Mann-Whitney test, which gave a value of $U=18470.00$ and $p=0.0084$, a statistically significant difference (see - Table 3).

We did not observe a significant association between inadequate protein intake $(p=0.78)$, inadequate intake of saturated fats $(p=0.97)$, inadequate intake of lipids $(p=0.43)$, and inadequate intake of monounsaturated fats $(p=0.79)$, but there was important significance between BPPV and inadequate fiber intake ( $p=0.03$; - Table 4).

\section{Discussion}

In this study, we observed the association of BPPV with a diet of inadequate carbohydrate intake, rich in polyunsaturated fatty acids, and insufficient fiber intake.

The elderly often have reduced appetite and energy expenditure, which can occur along with a decline of biological

Table 1 Full distribution of the number of patients with BPPV and food habits

\begin{tabular}{|l|l|l|}
\hline \multirow{2}{*}{ Food habits } & \multicolumn{2}{|l|}{ BPPV } \\
\cline { 2 - 3 } & Yes (\%) & No (\%) \\
\hline Inadequate nutrition & $37(31.62)$ & $97(26.21)$ \\
\hline Adequate nutrition & $80(68.37)$ & $273(73.78)$ \\
\hline Total & 117 & 370 \\
\hline
\end{tabular}

Abbreviation: ARR, absolute risk reduction; BPPV, benign paroxysmal positional vertigo; $\mathrm{NNH}$, number needed to harm.

Note: Odds ratio $=1.3017$; confidence interval 0.8272-2.0483; ARR

$=5.41 \% ; \mathrm{NNH}=19 ; \mathrm{X}_{\text {corr }}^{2}=1.303(p=0.3064)$.
Table 2 Full distribution of the number of patients with BPPV and inadequate carbohydrate consumption

\begin{tabular}{|l|l|l|}
\hline & \multicolumn{2}{|l|}{ BPPV } \\
\hline Inadequate carbohydrates & Yes (\%) & No (\%) \\
\hline Yes & $102(87.17)$ & $330(89.18)$ \\
\hline No & $15(12.82)$ & $40(10.81)$ \\
\hline Total & 117 & 370 \\
\hline
\end{tabular}

Abbreviation: BPPV, benign paroxysmal positional vertigo.

Note: $U=19351.50$ ( $p=0.0419)$.

and physiological functions, reduction of lean body mass, and changes in cytokine and hormonal levels. Other disturbances include changes in fluid electrolyte regulation, delayed gastric emptying, and diminished senses of smell and taste. In addition, pathologic changes of aging such as chronic diseases and psychological illness can lead to bad nutrition in the elderly. Nutritional assessment is important to identify, along with treating patients at risk. ${ }^{8}$

Vertigo, tinnitus, and hearing loss are common complaints among the elderly in industrial countries. Numerous agents are known to incite vertigo, tinnitus, and hearing loss, such as hyperinsulinemia and hyperlipidemia. According to the study of Kaźmierczak and Doroszewska, ${ }^{22}$ who assessed the occurrence of hyperinsulinemia and hyperlipidemia in patients suffering from vertigo, tinnitus, or hearing loss of unknown origin, only hyperlipoproteinemia did not differ between patients and control subjects. However, the authors concluded that disturbances of metabolism by glucose, such as diabetes mellitus and hyperinsulinemia, may be responsible for inner ear diseases, whereas the disturbance of lipid metabolism remains vague. Micronutrient insufficiency and high saturated fat intake have been associated with chronic diseases. $^{23}$ The study also reported that disturbances of glucose may be responsible for inner ear diseases. ${ }^{23}$ We also detected an excess of carbohydrates; these nutrients are interconvertible, raising each other through degradation of its components: $85 \%$ excess carbohydrate becomes fats (lipids) in the individual by the liver, increasing the lipids, cholesterol, and triglycerides in the blood, which may cause accumulation of sodium and potassium in the inner ear.

Table 3 Full distribution of the number of patients with BPPV and diet rich in polyunsaturated fatty acids

\begin{tabular}{|l|l|l|}
\hline & \multicolumn{2}{|l|}{ BPPV } \\
\hline Polyunsaturated fat & Yes (\%) & No (\%) \\
\hline $\begin{array}{l}\text { Diet rich in polyunsaturated } \\
\text { fatty acids }\end{array}$ & $82(70.08)$ & $289(78.10)$ \\
\hline $\begin{array}{l}\text { Normal diet in polyunsaturated } \\
\text { fatty acids }\end{array}$ & $35(29.91)$ & $81(21.89)$ \\
\hline Total & 117 & 370 \\
\hline
\end{tabular}

Abbreviation: BPPV, benign paroxysmal positional vertigo. Note: $U=18,470.00(p=0.0084)$. 
Table 4 Frequency of BPPV in relation to inadequate intake of protein, saturated fats, monounsaturated fats, lipids, and fibers

\begin{tabular}{|l|l|l|l|}
\hline Inadequate nutrition & BPPV, $\boldsymbol{n}$ (\%) & No BPPV, $\boldsymbol{n}(\%)$ & $\boldsymbol{p}$ Value \\
\hline Inadequate protein $^{\mathrm{a}}$ & 101 & 325 & 0.7 \\
\hline Inadequate saturated fat $^{\mathrm{b}}$ & 117 & 368 & 0.97 \\
\hline Inadequate lipids $^{\mathrm{C}}$ & 35 & 95 & 0.43 \\
\hline $\begin{array}{l}\text { Inadequate } \\
\text { monounsaturated fat }^{\mathrm{d}}\end{array}$ & 82 & 266 & 0.79 \\
\hline Inadequate fiber $^{\mathrm{e}}$ & 117 & 356 & 0.03 \\
\hline
\end{tabular}

Abbreviation: BPPV, benign paroxysmal positional vertigo.

${ }^{\mathrm{a}} \mathrm{X}_{\text {corr }}^{2}=0.186$

${ }^{\mathrm{b}} \mathrm{C}$ (Yates) $=0.010$

${ }^{c} X^{2}$ corr $=0.816$.

${ }^{d} X^{2}$ corr $=0.142$.

${ }^{\mathrm{e}} \mathrm{G}$ (Yates) $=4.624$.

Huffman et al confirmed our data showing that a lack of fiber leaves the human body unprotected, without the minimum number of regulators provided by a good diet. ${ }^{23}$ Fiber has an effect on lipid metabolism (propionate) and glucose (acetate, propionate, and butyrate), delaying absorption of glucose and starch hydrolysis, helping to maintain electrolyte balance of blood capillaries and also assisting the vestibulecochlear apparatus health.

British dietary recommendations are to decrease total fat intake to less than $30 \%$ of daily energy consumption and saturated fat to less than $10 \%$. The energy and fat intake seems to be reduced on the diet rich in polyunsaturated fatty acids. Insulin sensitivity and plasma low-density lipoprotein cholesterol concentrations are improved with a diet rich in polyunsaturated fatty acids compared with the diet rich in saturated fatty acids. ${ }^{24}$ However, other literature has reported that the elderly interviewed in large urban centers of Brazil have not joined the new trend of developed countries; consumption of traditional foods were replaced by processed foods of easy preparation causing dyslipidemia and excess of sodium, damaging the natural physiology chemical level in the inner ear among other comorbidities. ${ }^{25}$

In this study, we detected a diet high in polyunsaturated fatty acids (-Table 3 ). Reviewing the literature, we could observe that polyunsaturated fatty acids, when processed (hydrogenated), can be transformed into trans fats, which are harmful to health. However, we cannot analyze this information by itself; an individual who consumes excess fat (even good fat) and carbohydrates can still eat a low concentration of dietary fiber, which is likely to have dyslipidemia affects in the ear. Even though not much data regarding disorders of lipid metabolism exist in the literature, the ingestion of high amounts of polyunsaturated fats and trans fat could be related in part to lipid metabolism disorders. ${ }^{26}$

Mantello et al wrote that the changes in glucose metabolism are the main metabolic changes that lead to vestibulocochlear disorders. ${ }^{27}$ As the labyrinthine structures possess an intense metabolic activity, glucose is necessary for energy production and for maintaining proper concentrations of sodium and potassium in the endolymph. ${ }^{27}$ Some habits, such as alcohol, tobacco, sugar, salt, saturated fats, and caffeine, in addition to physical inactivity, should be banned from the lives of patients with vertigo because they can exacerbate symptoms of cochleovestibular and make vestibular compensation even slower. ${ }^{28}$ We suggest that the same procedures are taken in cases of BPPV, intensely studied here, for the same reasons cited above.

Through these results, we emphasize the importance of a multidisciplinary care team, expanding the procedures and results to prevention and treatment and minimizing episodes of recurrent BPPV in the elderly.

\section{Conclusion}

The association between BPPV with inadequate carbohydrate intake and a diet rich in polyunsaturated fatty acids and inadequate fiber intake has been observed. These associations deserve more in-depth study.

These data represent an important tool for better understanding the overall health and comorbidities of the elderly, assisting with the reasoning and awareness of a necessary change in their lifestyle; through guidelines and nutritional treatments, alongside multidisciplinary care, the team can help to decrease hearing symptoms of BPPV.

This study showed the importance of further studies associating the relationship between BPPV and the types of food habits. Further research is needed to develop a prevention and rehabilitation of BPPV with associate food habits.

\section{References}

1 Corrêa Leite ML, Nicolosi A, Cristina S, Hauser WA, Pugliese P, Nappi G. Dietary and nutritional patterns in an elderly rural population in Northern and Southern Italy: (I). A cluster analysis of food consumption. Eur J Clin Nutr 2003;57(12): 1514-1521

2 Jacques PF, Tucker KL. Are dietary patterns useful for understanding the role of diet in chronic disease? Am J Clin Nutr 2001;73(1):1-2

3 León-Muñoz LM, Guallar-Castillón P, Graciani A, et al. Dietary habits of the hypertensive population of Spain: accordance with 
the DASH diet and the Mediterranean diet. J Hypertens 2012; 30(7):1373-1382

4 Marchiori LLM, Melo JJ, Possette FLF, Correa AL. Comparison of frequency of vertigo in elderly with and without arterial hypertension. Int Arch Otorhinolaryngol 2010;4:456-460

5 Cabral GTR, Correa LB, Silveira SR, Lopes RP. Interferência da queixa de tontura na qualidade de vida dos idosos cadastrados na UBS do bairro Araçás, Vila Velha/ES. ActaOrl 2009;27(2):58-63

6 Maarsingh OR, Dros J, Schellevis FG, van Weert HC, Bindels PJ, Horst HE. Dizziness reported by elderly patients in family practice: prevalence, incidence, and clinical characteristics. BMC Fam Pract 2010;11(11):2

7 Marchiori LLM, Rego F, Almeida E. Queixa de vertigem e hipertensão arterial. Rev Cefac 2007;9(1):116-121

8 Chapman IM. Nutritional disorders in the elderly. Med Clin North Am 2006;90(5):887-907

9 Ahmed T, Haboubi N. Assessment and management of nutrition in older people and its importance to health. Clin Interv Aging 2010; 5(5):207-216

10 Stratton RJ, Green CJ, Elia M. Disease-Related Malnutrition. An Evidence-Based Approach to Treatment. Oxford, UK: CABI; 2003

11 Bittar RSM, Bottino MA, Zerati FE, Moraes CLO, Cunha AU, Bento RF. Prevalência das alterações metabólicas em pacientes portadores de queixas vestibulares. Rev Bras Otorrinolaringol 2003;69(1):64-69

12 Bittar R, Saraiva M, Bottino MA, Simoceli L, Venosa AR. Vestibular impairment secondary to glucose metabolic disorders: reality or myth? Rev Bras Otorrinolaringol 2004;70(6):800-805

13 Ganança MM, Caovilla HH, Munhoz MSL, Silva MLG. Alterações da audição e do equilíbrio corporal no idoso. Rev Bras Med 1999; 56(10):995-1011

14 Bhattacharyya N, Baugh RF, Orvidas L, et al; American Academy of Otolaryngology-Head and Neck Surgery Foundation. Clinical practice guideline: benign paroxysmal positional vertigo. Otolaryngol Head Neck Surg 2008;139(5, Suppl 4):S47-S81

15 Cho EI, White JA. Positional vertigo: as occurs across all age groups. Otolaryngol Clin North Am 2011;44(2):347-360, viii

16 Marconi MA, Lakatos EM. Fundamentos de metodologia científica. 7th ed. São Paulo, Brazil: Atlas; 2010

17 Spidurso WW. Dimensões físicas do envelhecimento. Barueri São Paulo, Brazil: Manole; 2005
18 Slimani N, Deharveng G, Charrondière RU, et al. Structure of the standardized computerized 24-h diet recall interview used as reference method in the 22 centers participating in the EPIC project. European Prospective Investigation into Cancer and Nutrition. Comput Methods Programs Biomed 1999;58(3): 251-266

19 Avanutri. Software for Windows. Rio de Janeiro, Brazil: Avanutri Informática; 2014

20 Institute of Medicine. Dietary Reference Intakes for Energy, Carbohydrate, Fiber, Fat, Fatty Acids, Cholesterol, Protein, and Amino Acids: Summary Tables. Washington, DC: The National Academies Press; 2006. Available at: http://www.nap.edu/openbook.php? record_id=10490\&page $=1319$. Accessed in December 15, 2014

21 Dix MR, Hallpike CS. The pathology, symptomatology and diagnosis of certain common disorders of the vestibular system. Ann Otol Rhinol Laryngol 1952;61(4):987-1016

22 Kaźmierczak H, Doroszewska G. Metabolic disorders in vertigo, tinnitus, and hearing loss. Int Tinnitus J 2001;7(1): $54-58$

23 Huffman FG, Vaccaro JA, Zarini GG, Biller D, Dixon Z. Inadequacy of micronutrients, fat, and fiber consumption in the diets of Haitian-, African- and Cuban-Americans with and without type 2 diabetes. Int J Vitam Nutr Res 2012;82(4): 275-287

24 Summers LK, Fielding BA, Bradshaw HA, et al. Substituting dietary saturated fat with polyunsaturated fat changes abdominal fat distribution and improves insulin sensitivity. Diabetologia 2002; 45(3):369-377

25 Lima Filho DO, Sproesser LR, Lima MFEM, Lucchese T. Comportamento alimentar do consumidor idoso. Revista de negócios 2008; 13(4):27-39

26 Manninen V, Elo MO, Frick MH, et al. Lipid alterations and decline in the incidence of coronary heart disease in the Helsinki Heart Study. JAMA 1988;260(5):641-651

27 Mantello EB, Moriguti JC, Júnior ALR, Ferrioli E. Efeito da reabilitação vestibular sobre a qualidade de vida de idosos labirintopatas. Rev Bras Otorrinolaringol 2008;74(2):1-14

28 Ducan B, Schmidt M, Giugliani E. Medicina ambulatorial: condutas de atenção primaria baseada em evidencias. 3rd ed. Porto Alegre, Brazil: Artmed; 2004 